\title{
Article \\ Silencing a Simple Extracellular Leucine-Rich Repeat Gene OsI-BAK1 Enhances the Resistance of Rice to Brown Planthopper Nilaparvata lugens
}

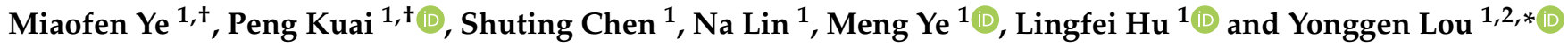 \\ 1 State Key Laboratory of Rice Biology \& Ministry of Agriculture Key Lab of Agricultural Entomology, \\ Institute of Insect Sciences, Zhejiang University, Hangzhou 310058, China; 11616070@zju.edu.cn (M.Y.); \\ kpchen7493@163.com (P.K.); shut_chen@163.com (S.C.); lin_na@zju.edu.cn (N.L.); \\ mengye@tricaas.com (M.Y.); lingfeihu@zju.edu.cn (L.H.) \\ 2 Hainan Institute, Zhejiang University, Sanya 572025, China \\ * Correspondence: yglou@zju.edu.cn; Tel.: +86-571-88982622 \\ + These authors contributed equally to this work.
}

check for updates

Citation: Ye, M.; Kuai, P.; Chen, S.; Lin, N.; Ye, M.; Hu, L.; Lou, Y. Silencing a Simple Extracellular Leucine-Rich Repeat Gene OsI-BAK1 Enhances the Resistance of Rice to Brown Planthopper Nilaparvata lugens. Int. J. Mol. Sci. 2021, 22, 12182. https://doi.org/10.3390/ ijms222212182

Academic Editor: Marcello Iriti

Received: 19 October 2021

Accepted: 6 November 2021

Published: 10 November 2021

Publisher's Note: MDPI stays neutral with regard to jurisdictional claims in published maps and institutional affiliations.

Copyright: (C) 2021 by the authors Licensee MDPI, Basel, Switzerland. This article is an open access article distributed under the terms and conditions of the Creative Commons Attribution (CC BY) license (https:// creativecommons.org/licenses/by/ $4.0 /)$.

\begin{abstract}
Many plant proteins with extracellular leucine-rich repeat (eLRR) domains play an important role in plant immunity. However, the role of one class of eLRR plant proteins-the simple eLRR proteins-in plant defenses against herbivores remains largely unknown. Here, we found that a simple eLRR protein OsI-BAK1 in rice localizes to the plasma membrane. Its expression was induced by mechanical wounding, the infestation of gravid females of brown planthopper (BPH) Nilaparvata lugens or white-backed planthopper Sogatella furcifera and treatment with methyl jasmonate or abscisic acid. Silencing OsI-BAK1 (ir-ibak1) in rice enhanced the BPH-induced transcript levels of three defense-related WRKY genes (OsWRKY24, OsWRKY53 and OsWRKY70) but decreased the induced levels of ethylene. Bioassays revealed that the hatching rate was significantly lower in $\mathrm{BPH}$ eggs laid on ir-ibak1 plants than wild-type (WT) plants; moreover, gravid BPH females preferred to oviposit on WT plants over ir-ibak1 plants. The exogenous application of ethephon on ir-ibak1 plants eliminated the BPH oviposition preference between WT and ir-ibak1 plants but had no effect on the hatching rate of $\mathrm{BPH}$ eggs. These findings suggest that OsI-BAK1 acts as a negative modulator of defense responses in rice to $\mathrm{BPH}$ and that $\mathrm{BPH}$ might exploit this modulator for its own benefit.
\end{abstract}

Keywords: rice; OsI-BAK1; Nilaparvata lugens; ethylene; plant defense responses; simple extracellular leucine-rich repeat protein

\section{Introduction}

When attacked by herbivorous insects, plants recognize patterns associated with damage and with herbivores via pattern recognition receptors (PRRs) and respond by activating a series of early signaling events: increasing cytosolic $\mathrm{Ca}^{2+}$ concentrations, triggering a burst of reactive oxygen species (ROS) and activating mitogen-activated protein kinase (MPK) cascades [1,2]. These early events trigger signaling pathways mediated by phytohormones consisting mainly of jasmonic acid (JA), ethylene (ET) and salicylic acid (SA), which reorganize the transcriptome, proteome and metabolome, respectively, of the plant and thereby enhance plants' resistance to herbivores [3-6].

Proteins with extracellular leucin-rich repeat (eLRR) domains are categorized into five classes, including polygalacturonase inhibitor protein (PGIP)-like proteins, leucine-rich repeat extensin-like proteins, leucine-rich repeat receptor-like proteins (LRR-RLPs), leucinerich repeat receptor-like kinases (LRR-RLKs) and simple eLRR domain proteins [7-9]. Many among the first four classes of eLRR proteins, especially LRR-RLKs and LRR-RLPs, have been reported to play an important role in defense responses of plants to pathogens and herbivores [10-12]. In Arabidopsis, for example, flagellin-sensitive 2 (FLS2), an LRR-RLK 
protein, binds flagellin peptide 22 , an elicitor secreted by bacteria $[13,14]$, and interacts with another LRR-RLK, brassinosteroid insensitive 1-associated kinase 1 (BAK1), to form a PRR complex, the FLS2-BAK1 complex [15]. The complex activates downstream of defenserelated signaling cascades and regulates plant defenses to pathogens [16,17]. In rice, an LRR-RLK, Xanthomonas resistance 21 (XA21), recognizes tyrosine-sulfated protein RaxX (required for activating XA21-mediated immunity X) from Xanthomonas oryzae pv. oryzae $(\mathrm{Xoo})$ and then induces the production of ROS and ethylene and enhances the resistance of rice to Xoo [18-21]. A rice LRR-RLK, OsLRR-RLK1, acts upstream of the MPK cascades and positively regulates both the biosynthesis of herbivore-induced JA and ethylene and plants' resistance to striped stem borer (SSB) Chilo suppressalis [22]. In cowpeas (Vigna unguiculata), an LRR-RLP has been reported to function as a receptor of inceptins, elicitors that exist in the oral secretions of many Lepidopteran species; this receptor is sufficient to confer inceptin-induced responses and enhances the defense responses against armyworms Spodoptera exigua [23]. Moreover, the fitness of leaf beetles Phaedon cochleariae fed on PGIP (AtPGIP1 or AtPGIP2)-deficient plants is higher than the fitness of those fed on wild-type (WT) plants [24].

Simple eLRR proteins have also been reported to regulate the defense responses of plants to pathogens. For example, some simple eLRR genes, such as SILRP in Solanum lycopersicum [25], SbLRR and SbLRR2 in Sorghum bicolor [26,27] and NtLRP1 and NtLRR1 in Nicotiana tabacum [28,29], are responsive to pathogen infections. In pepper Capsicum annuum, a simple eLRR protein, CaLRR1, interacts with a hypersensitive-induced reaction (HIR) protein, CaHIR1, and two pathogenesis-related proteins, CaPR10 and CaPR4b, and then regulates the plant defense responses [30]. A simple eLRR protein in rice, OsLRR1, whose transcript levels are induced by pathogen infection, wounding and treatment with SA or JA, enters the endosomal pathway and interacts with plasma membrane-localized OsHIR1; the ectopic expression of OsLRR1 in Arabidopsis thaliana enhances the resistance of plants to Pseudomonas syringae pv. tomato DC3000 (Pst DC3000) by increasing the transcript levels of the defense genes related to the SA (AtPR1 and AtPR2)- and JA (AtPDF1.2)mediated pathways [7,9]. Expressing OsLRR1 in Chinese cabbage Brassica rapa L. subsp. pekinensis enhances plants' resistance to bacterial soft rot by activating defense-related genes (PDF1, BrPGIP2, glucanase genes MERI5B and Meri-5 and hypersensitive cell death marker gene Athsr3) [7]. Moreover, OsLRR1 is required for XA21-mediated rice defense responses to Xoo [31]. However, whether and how simple eLRR proteins regulate plants' defenses to herbivores remains largely unknown.

Rice (Oryza sativa L.), one of the most important food crops in the world, suffers heavily from predation by many herbivorous insects. Brown planthopper (BPH) Nilaparvata lugens (Stål), a major hemipteran insect pest, damages rice mainly by feeding on phloem sap, laying eggs in plant tissues and transmitting viruses [32]. Previous studies have revealed that, when rice plants are infested by $\mathrm{BPH}$, they respond by activating a complex signaling network, primarily MPK cascades and pathways mediated by JA, SA, ethylene and hydrogen peroxide $\left(\mathrm{H}_{2} \mathrm{O}_{2}\right)$ [33-38]; the defense responses, such as the accumulation of trypsin proteinase inhibitors (TrypPIs) and the release of herbivore-induced plant volatiles (HIPVs), may influence the performance of conspecific and non-conspecific herbivores directly, as well as indirectly, by regulating the role of the natural enemies of herbivores [22,36-42]. Although some eLRR proteins play an important role in regulating rice plants' defense responses to pathogens and herbivores, as stated above, whether simple eLRR proteins are involved in the defense responses of rice to herbivores remains unclear.

In this study, we identified an herbivore-induced simple eLRR protein gene in rice, OsI-BAK1, which responds to infestation by gravid BPH females [41]. To investigate its role in $\mathrm{BPH}$-induced defenses in rice, we obtained stably transformed rice plants rendered deficient in OsI-BAK1 by RNA interference (RNAi). Combining molecular biology, phytohormone analyses and bioassays, we demonstrate that OsI-BAK1 positively regulates the biosynthesis of $\mathrm{BPH}$-induced $\mathrm{ET}$ and decreases the resistance of rice to $\mathrm{BPH}$. 


\section{Results}

\subsection{Isolation and Characterization of OsI-BAK1}

The transcriptome data from rice plants infested by gravid females of $\mathrm{BPH}$ showed that the transcript level of a simple eLRR gene was significantly upregulated [41]. By cloning this gene, we found that its sequence was $100 \%$ identical to the previously reported OsI-BAK1 (brassinosteroid insensitive 1-associated kinase 1) [43]. The sequence analysis found that OsI-BAK1 includes an open reading frame of $657 \mathrm{bp}$; this frame, which encodes a protein of 219 amino acids with a predicted molecular weight of $23.64 \mathrm{kDa}$, contains a signal peptide and five LRR motifs (Figures 1a and S3). BLASTP searches in the NCBI showed that OsI-BAK1 shares a high similarity with simple eLRR proteins, such as ObLRR1like (96.92\% identity) in Oryza brachyantha, BdLRR1 (94.76\%) in Brachypodium distachyon, AtLRR2 (94.76\%) in Aegilops tauschii subsp. Strangulate and TdLRR2-like-1 (87.61\%) and TdLRR2-like-2 (87.61\%) in Triticum dicoccoides (Figure 1b).

A subcellular localization assay using a fusion gene (OsI-BAK1 with green fluorescent protein) showed that the fluorescent signal emitted from the fusion protein was observed on the plasma membrane; this signal overlapped with the fluorescent signal emitted from the membrane-localized positive control protein AtPIP2A (Figure 1c). The results suggest that OsI-BAK1 was a plasma membrane-localized eLRR protein and may play a role in signal recognition and transduction.

\subsection{Herbivore Infestation, Wounding and JA and Abscisic Acid Treatment Enhance Transcript Levels of OsI-BAK1}

Compared with the corresponding controls, all of the measured treatments- $\mathrm{BPH}$ infestation, white-backed planthopper (WBPH) infestation, mechanical wounding and treatment with methyl jasmonate (MeJA) or abscisic acid (ABA) — enhanced the transcript level of OsI-BAK1 in plants (Figure 2). Unlike BPH infestation and mechanical wounding, both of which induced the expression of OsI-BAK1 quickly starting $1.5 \mathrm{~h}$ after treatment (Figure 2a,b), the other three treatments induced the expression of OsI-BAK1 relatively later, starting $8 \mathrm{~h}$ after treatment (Figure $2 \mathrm{c}-\mathrm{e}$ ). Moreover, the effect of mechanical wounding on the expression of OsI-BAK1 lasted for less time, peaking at $12 \mathrm{~h}$ and returning to control levels at $48 \mathrm{~h}$, compared to the effect of other treatments on the expression of OsI-BAK1 (in these, the expression of OsI-BAK1 peaked $48 \mathrm{~h}$ after treatment).

\subsection{Silencing OsI-BAK1 in Rice}

To investigate the function of OsI-BAK1 in herbivore-induced defense responses in rice, we obtained two homozygous OsI-BAK1-silenced lines (irIBAK1-1 and irIBAK1-2) with a single insertion (Figure S4a, See Supplementary Materials). The transcriptional analysis showed that the transcript level of OsI-BAK1 in the two ir-ibak1 lines was only $6.9-8.5 \%$ of that in WT plants 0 and $8 \mathrm{~h}$ after BPH infestation (Figure 3a).

Based on the database from the Rice Genome Annotation Project (http: / / rice.plantbiology. msu.edu/index.shtml; accessed on 29 October 2019), five genes shared high similarities in nucleotide sequences with OsI-BAK1: LOC_Os01g59440 (92.31\% identity), LOC_Os11g31540 (90.00\%), LOC_Os01g17250 (89.51\%), LOC_Os11g31530 (89.09\%) and LOC_Os05g41230 $(82.42 \%)$. Among these five genes, two (LOC_Os11g31530 and LOC_Os05g41230) showed such low transcript levels that their transcripts were not detected; the other three genes were not co-silenced by the RNAi construct in the transgenic plants (Figure S4b-d). Therefore, the specificity of the RNAi sequence was high. Compared with WT plants, ir-ibak1 plants showed only a slight difference in growth phenotypes (Figure 3b): the root length of ir-ibak1 plants 30 or 40 days old was longer than the root length of WT plants (Figure 3c), whereas no difference was observed in shoot height, plant mass or chlorophyll contents between WT and ir-ibak1 plants (Figure 3d-f). 
(a)

(b)
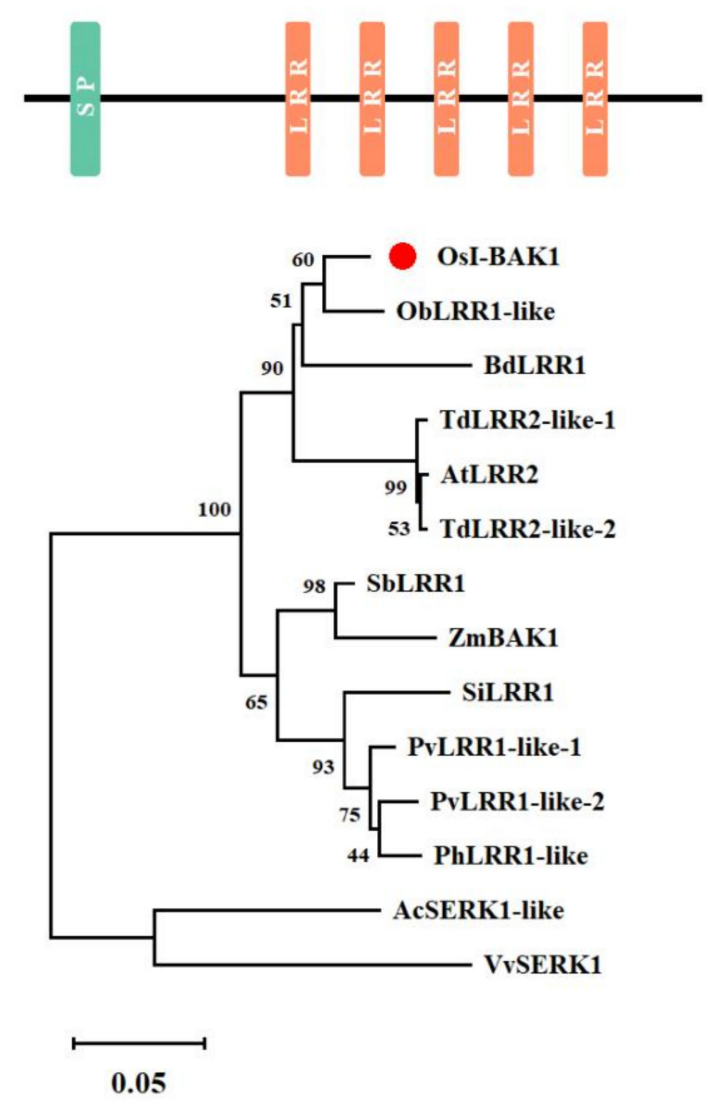

(c) OsI-BAK1-GFP AtPIP2A-mCherry Bright Overlay

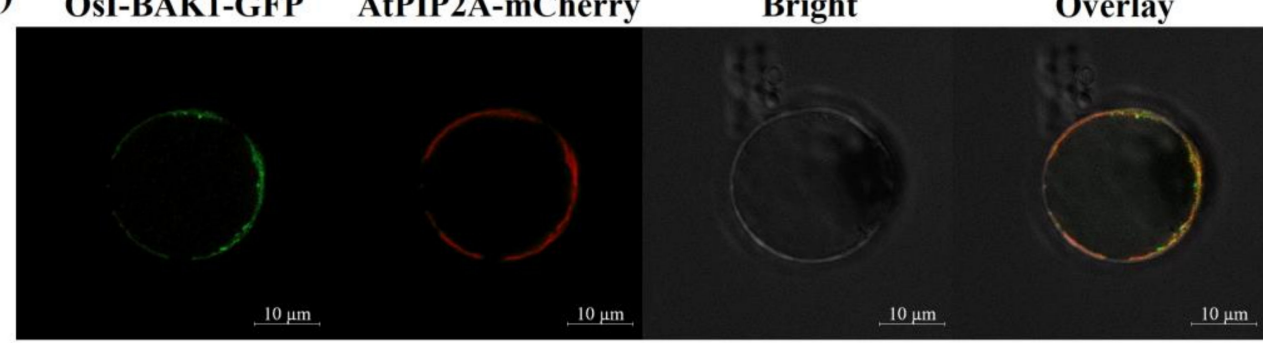

Figure 1. Structure, phylogenetic relationship and subcellular localization of OsI-BAK1. (a) Schematic structure of OsI-BAK1. SP, signal peptide; LRR, leucin-rich repeat. (b) Sequence alignment of OsI-BAK1 and its homologs. Species abbreviations are included before the protein names: Ac, Ananas comosus; At, Aegilops tauschii subsp. strangulate; Bd, Brachypodium distachyon; Ob, Oryza brachyantha; Os, Oryza sative; Ph, Panicum hallii; Pv, Panicum virgatum; Sb, Sorghum bicolor; Si, Setaria italica; Td, Triticum dicoccoides; Vv, Vitis vinifera and Zm, Zea mays. Plant species and accession numbers from the NCBI database are as follows: AcSERK1-like, XP_020105022.1; AtLRR2, XP_020193068.1; BdLRR1, XP_003562364.1; ObLRR1-like, XP_006650233.1; OsI-BAK1, XP_015631230.1; PhLRR1-like, XP_025793013.1; PvLRR1-like-1, XP_039825633.1; PvLRR1-like-2, XP_039785598.1; SbLRR1, XP_002467662.1; SiLRR1, XP_004983941.1; TdLRR2-like-1, XP_037465236.1; TdLRR2-like-2, XP_037458478.1; VvSERK1, XP_002263235.1 and ZmBAK1, NP_001148919.1. The red dot indicates OsI-BAK1. The scale bar represents 0.05 amino acid substitution per site in the primary structure. (c) Subcellular localization of OsI-BAK1. Polyethylene glycol-mediated transient expression in rice protoplasts of OsI-BAK1-GFP and AtPIP2A-mCherry. OsI-BAK1-GFP, green fluorescent protein (GFP) fluorescence from OsI-BAK1-GFP; AtPIP2A-mCherry, mCherry fluorescence from AtPIP2A-mCherry; Bright, bright field and Overlay, co-localization of the OsI-BAK1-GFP and AtPIP2A-mCherry proteins. Bars, $10 \mu \mathrm{m}$. 
(a)

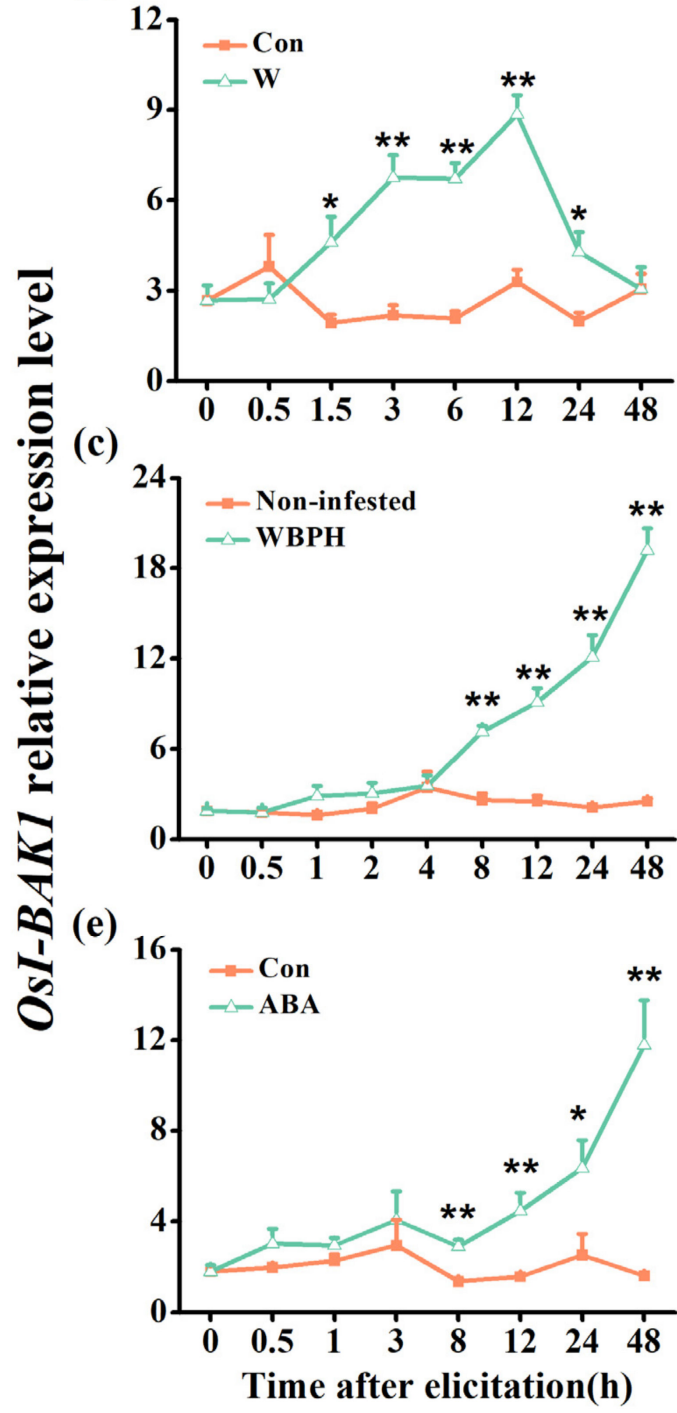

(b)



(d)



Figure 2. Relative expression levels of OsI-BAK1 in rice leaf sheaths after different treatments. Mean transcript levels (+SE, $\mathrm{n}=5$ ) of OsI-BAK1 in rice leaf sheaths that were mechanically wounded $(\mathrm{W},(\mathbf{a}))$, infested with gravid brown planthopper $(\mathrm{BPH})$ females $(\mathbf{b})$, gravid white-backed planthopper (WBPH) females (c) or treated with methyl jasmonate (MeJA) (d) or abscisic acid (ABA) (e). Noninfested, plants that were covered in an empty glass cylinder without BPH or WBPH; Con, control plants corresponding to mechanical wounding or MeJA or ABA treatment. Asterisks represent significant differences between the treatments and controls at each time point ${ }^{*} p<0.05$ and ${ }^{* *} p<0.01$; Student's $t$-tests).

\subsection{OsI-BAK1 Negatively Regulates the Transcript Level of Defense-Related WRKYS}

MPK cascades and WRKY transcription factors (TFs) are key regulators in plant defense responses $[44,45]$. Thus, we detected the kinase activity of two MPKs, OsMPK3 and OsMPK6, and the transcript levels of OsMPK3 and OsMPK6 [46,47], as well as of three WRKY genes (OsWRKY24, OsWRKY53 and OsWRKY70), all of which have been reported to play an important role in the defense responses of plants to pathogens or herbivores $[33,34,48,49]$ in ir-ibak1 and WT plants. The results showed that the transcript levels of OsMPK3 were higher in the ir-ibak1 lines than in WT plants at $1 \mathrm{~h}$ after BPH infestation (Figure 4a), whereas no difference was found in the transcript levels of OsMPK6 between WT and ir-ibak1 plants before or after BPH infestation (Figure S5a). Although BPH infestation induced the kinase activation of OsMPK3, it did not induce the kinase activation 
of OsMPK6; no difference in the kinase activation of both OsMPK3 and OsMPK6 was observed between the WT and ir-ibak1 lines (Figure S5b-d). Silencing OsI-BAK1 enhanced not only the BPH-induced transcript levels of OsWRKY24, OsWRKY53 and OsWRKY70 but, also, the constitutive transcript levels of OsWRKY53 (Figure 4b-d).

(a)

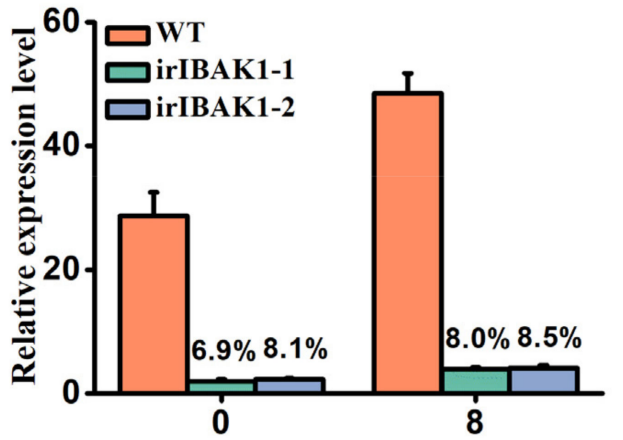

Time after elicitation(h)

(c)



(e)

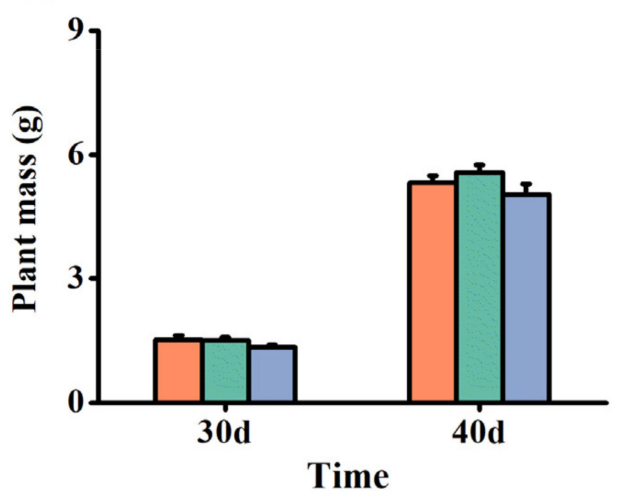

(b)



(d)

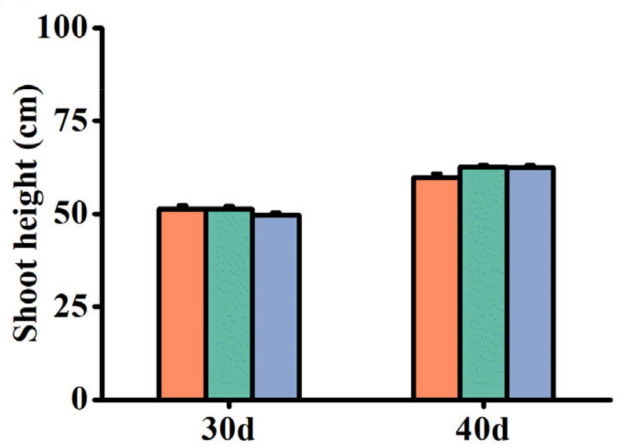

(f)

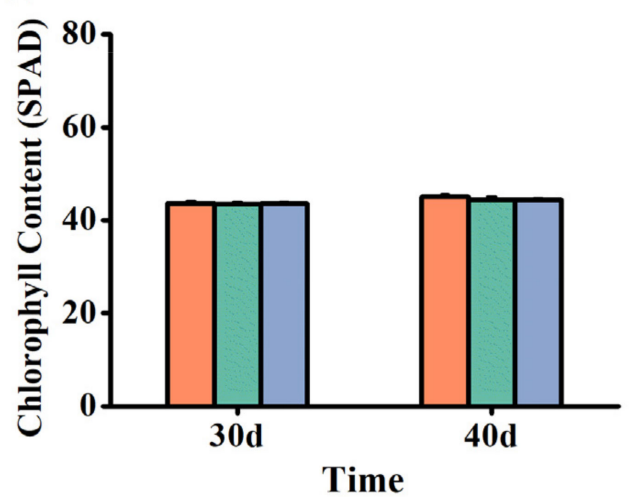

Figure 3. Transgenic lines silencing OsI-BAK1 and their growth phenotypes. (a) Mean expression levels (+SE, $\mathrm{n}=5$ ) of OsI-BAK1 in wild-type (WT) and ir-ibak1 plants at 0 and $8 \mathrm{~h}$ after BPH infestation. Percentages indicate the percentage of the expression levels of OsI-BAK1 in ir-ibak1 plants compared to the expression levels of OsI-BAK1 in WT plants. (b) The growth phenotype of 30- and 40-day-old WT and ir-ibak1 plants in the greenhouse. (c-f) Mean root length (c), shoot height (d), plant mass (e) and chlorophyll content (f) (+SE, n $=10)$ of WT and ir-ibak1 plants at 30 or 40 days old in the greenhouse. Different letters represent significant differences among the lines $(p<0.05$, Tukey's HSD post-hoc tests). 
(a)

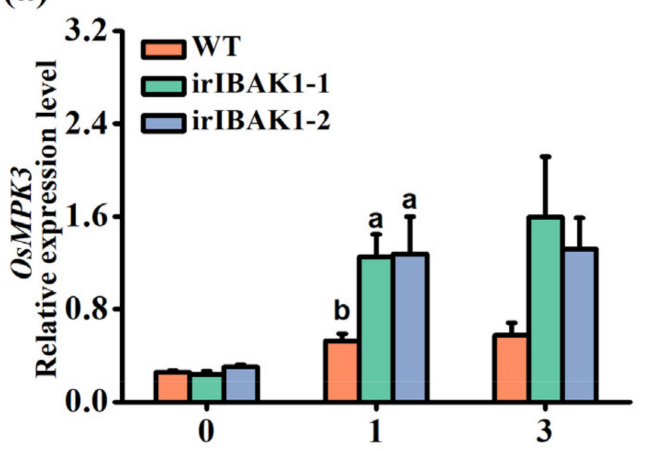

(c)



(b)

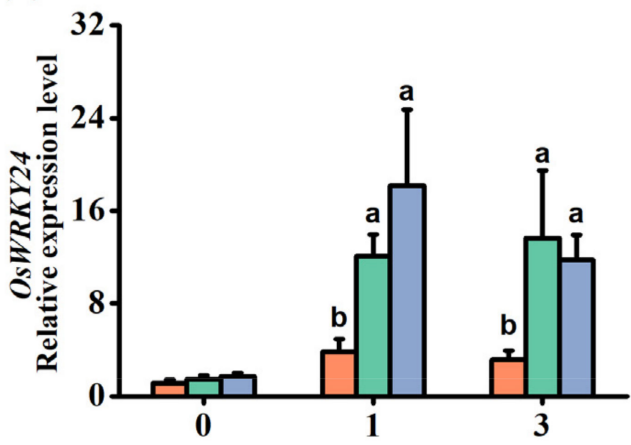

(d)

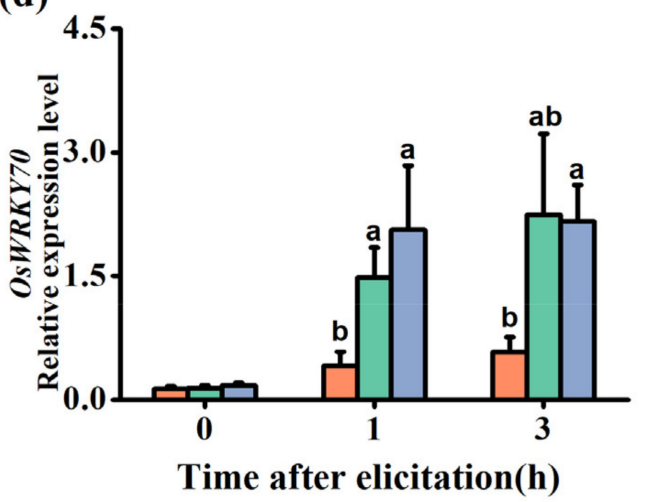

Figure 4. Silencing OsI-BAK1 enhances the transcript levels of defense-related MPKs and WRKYs. Mean expression levels (+SE, $\mathrm{n}=5$ ) of OsMPK3 (a), OsWRKY24 (b), OsWRKY53 (c) and OsWRKY70 (d) in WT and ir-ibak1 plants after gravid BPH female infestation. Different letters represent significant differences among the lines ( $p<0.05$, Tukey's HSD post-hoc tests).

\subsection{Silencing OsI-BAK1 Reduces the Accumulation of BPH-Induced Ethylene}

The JA-, SA-, ET-, ABA- and $\mathrm{H}_{2} \mathrm{O}_{2}$-mediated signaling pathways regulate the resistance of rice to $\mathrm{BPH}[36,39,50]$. Therefore, we investigated the changes in the concentrations of these six signal molecules in WT and ir-ibak1 plants before and after they were infested by BPH. A remarkable decrease in the ET levels in transgenic plants compared with WT plants was observed when plants were infested with gravid females of BPH for 24,48 or $72 \mathrm{~h}$ (Figure 5a). Consistently, the transcript levels of two genes related to ET biosynthesis (OsACO1 and OsACS1) [51,52] and of one transcription factor, OsERF2, which might be related to the ET pathway [53], decreased in the ir-ibak1 lines compared with WT plants (Figure $5 b-d$ ). However, although BPH induced the accumulation of JA, JA-Ile, ABA and $\mathrm{H}_{2} \mathrm{O}_{2}$ in plants, no difference in the levels of these signal molecules was observed between the WT and ir-ibak1 plants, except for the constitutive level of $\mathrm{H}_{2} \mathrm{O}_{2}$, which was 1.3-fold higher in irIBAK1-1 plants than in WT plants (Figure S6a-d). Moreover, silencing OsI-BAK1 did not influence the SA accumulation in plants (Figure S6e).

\subsection{Silencing OsI-BAK1 Enhances the Resistance of Rice to BPH}

The bioassays revealed that gravid BPH females preferred to lay eggs on WT plants over ir-ibak1 plants: the number of eggs laid on irIBAK1-1 and irIBAK1-2 plants was only $66.38 \%$ and $66.52 \%$ of the number laid on WT plants (Figure $6 \mathrm{a}, \mathrm{b}$ ). Moreover, the hatching rate of $\mathrm{BPH}$ eggs laid on ir-ibak1 plants was significantly lower than that of $\mathrm{BPH}$ eggs laid on WT plants (Figure 6c). However, silencing OsI-BAK1 did not influence the survival rate of BPH nymphs (Figure 6d). 
(a)

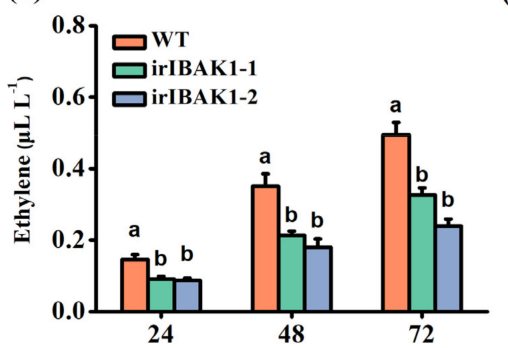

(c)

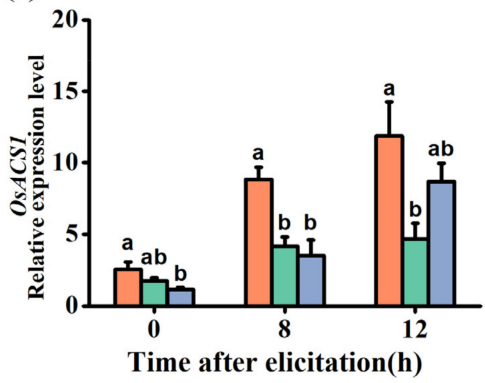

(b)

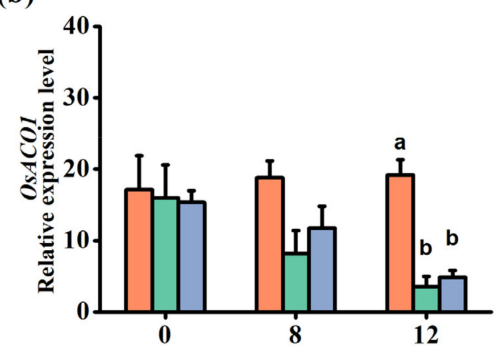

(d)

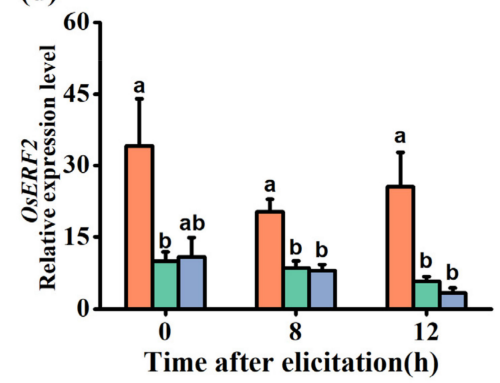

Figure 5. Silencing OsI-BAK1 decreases the BPH-induced levels of ethylene (ET). (a) Mean levels (+SE, $\mathrm{n}=8$ ) of ET emitted from individual WT and ir-ibak1 plants at 24, 48 and $72 \mathrm{~h}$ after gravid BPH female infestation. (b-d) Mean transcript levels (+SE, n = 5) of OsACO1 (b), OsACS1 (c) and OsERF2 (d) in WT and ir-ibak1 plants at different time points after they were infested by gravid BPH females. Different letters represent significant differences among the lines ( $p<0.05$, Tukey's HSD post-hoc tests).

(a)

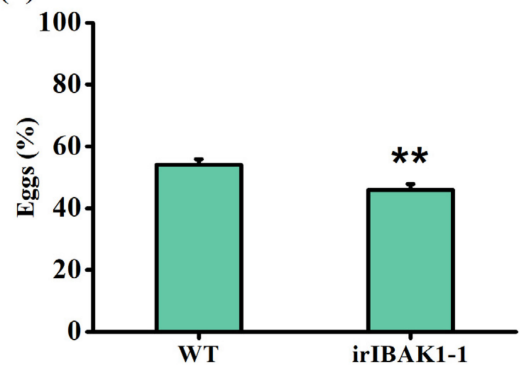

(c)

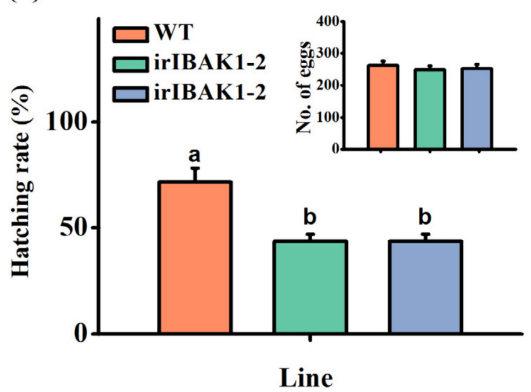

(b)

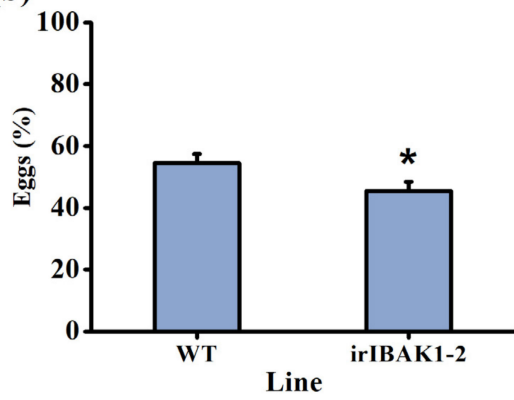

(d)

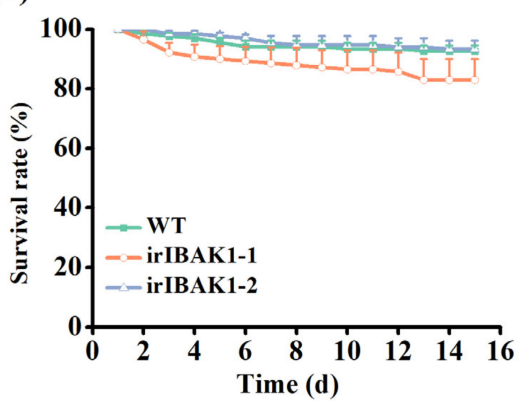

Figure 6. Silencing OsI-BAK1 enhances the resistance of rice to BPH. $(\mathbf{a}, \mathbf{b})$ Mean percentage $(+\mathrm{SE}, \mathrm{n}=$ 10) of BPH eggs per plant on pairs of plants (WT versus irIBAK1-1 or irIBAK1-2) $48 \mathrm{~h}$ after the release of BPH. Asterisks represent significant differences between the WT and transgenic plants (irIBAK1-1 or irIBAK1-2) (* $p<0.05$ and ${ }^{* *} p<0.01$; Student's $t$-tests). (c) Mean hatching rate $(+\mathrm{SE}, \mathrm{n}=10)$ of $\mathrm{BPH}$ eggs laid on WT and ir-ibak1 plants. Inserts: mean number of BPH eggs $(+\mathrm{SE}, \mathrm{n}=10)$ per plant on WT and ir-ibak1 plants. Different letters indicate significant differences among the lines $(p<0.05$, Tukey's HSD post-hoc tests). (d) Mean survival rate (+SE, $\mathrm{n}=10)$ of BPH nymphs on WT and ir-ibak1 plants $0-16 \mathrm{~d}$ after the newly hatched nymphs were placed on the plants. 
To investigate whether the enhanced resistance of ir-ibak1 plants to BPH was due to their reduced emission of ET, we treated ir-ibak1 plants by spraying them with ethephon and carried out the bioassays as above. The data showed that the decrease in preference of BPH for ir-ibak1 plants was abolished when ir-ibak1 plants were individually sprayed thoroughly with $500-\mu \mathrm{M}$ or $1-\mathrm{mM}$ ethephon (Figure 7). However, spraying ethephon on ir-ibak1 plants with the same concentration did not affect the hatching rate of BPH eggs (Figure S7).

(a)

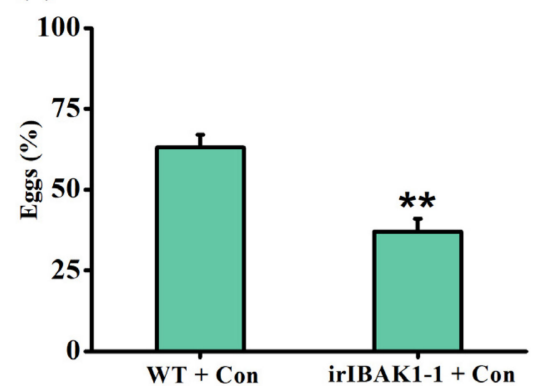

(c)

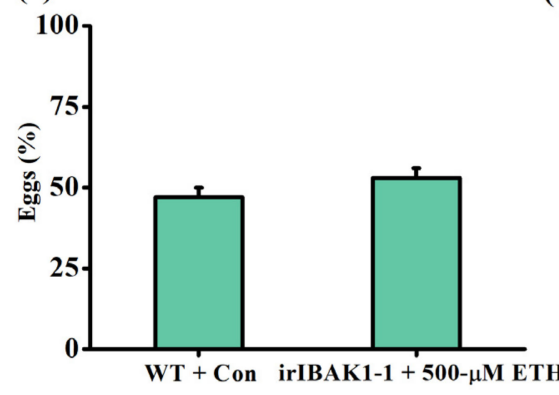

(e)

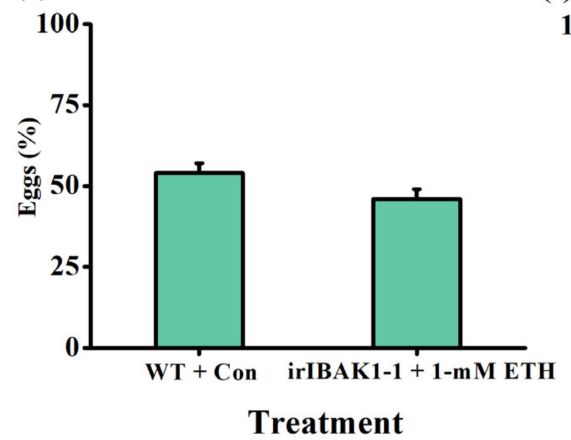

(b)

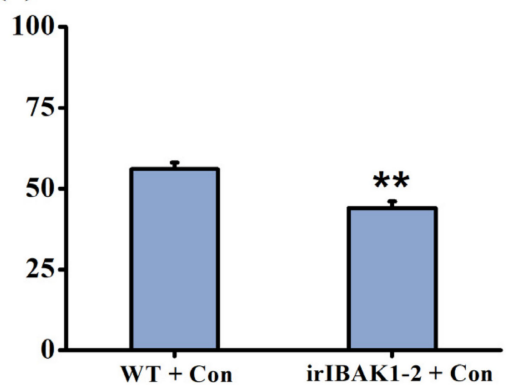

(d)



(f)

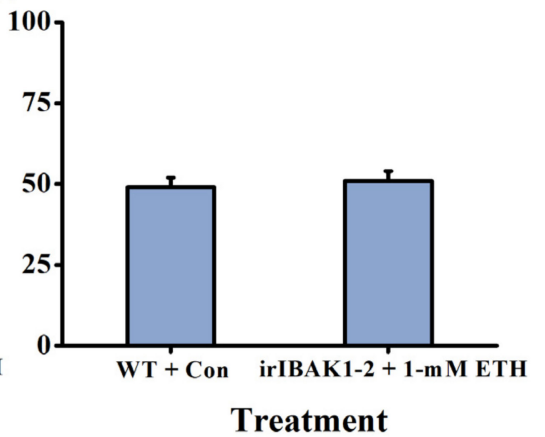

Figure 7. Spraying ethephon abolishes the difference in oviposition preference of BPH for WT and ir-ibak1 plants. $(\mathbf{a}, \mathbf{b})$ Mean percentage $(+\mathrm{SE}, \mathrm{n}=10)$ of $\mathrm{BPH}$ eggs per plant on pairs of plants (WT versus irIBAK1-1 or irIBAK1-2) that were sprayed with $\mathrm{ddH}_{2} \mathrm{O}$ (with $0.02 \%$ Tween-20) $48 \mathrm{~h}$ after the release of $\mathrm{BPH}$. (c-f) Mean percentage $(+\mathrm{SE}, \mathrm{n}=10)$ of $\mathrm{BPH}$ eggs per plant on pairs of plants, WT plants that were sprayed with $\mathrm{ddH}_{2} \mathrm{O}$ (with $0.02 \%$ Tween-20) versus irIBAK1-1 or irIBAK1-2 plants that were sprayed with $500-\mu \mathrm{M}$ ethephon $(\mathrm{ETH})(\mathbf{c}, \mathbf{d})$ or WT plants that were sprayed with $\mathrm{ddH}_{2} \mathrm{O}$ (with $0.02 \%$ Tween-20) versus irIBAK1-1 or irIBAK1-2 plants that were sprayed with 1-mM ETH $(\mathbf{e}, \mathbf{f}) 48 \mathrm{~h}$ after the release of BPH. Con, control solution. Asterisks represent significant differences between the treated plants and control plants (** $p<0.01$; Student's $t$-tests).

\section{Discussion}

Simple eLRR proteins have been reported to play an important role in the defense responses of plants to pathogens by influencing the defense-related signaling pathways $[9,30,54]$. In this study, we found that a simple eLRR gene in rice, OsI-BAK1, is induced by $\mathrm{BPH}$ or WBPH infestation, mechanical wounding and treatment with MeJA or ABA. Silencing 
OsI-BAK1 increased the transcript levels of defense-related genes OsMPK3, OsWRKY24, OsWRKY53 and OsWRKY70 and decreased the BPH-induced ET levels, which subsequently enhanced the resistance of rice to BPH. These results demonstrate that OsI-BAK1 functions as an important negative regulator in the defense responses of rice to $\mathrm{BPH}$.

Simple eLRR genes have been reported to exhibit specific expression patterns. For example, some simple eLRR genes, such as SILRP in Solanum lycopersicum [25], SLRR and SbLRR2 in Sorghum bicolor [26,27] and OsLRR1 in rice [9], are reportedly induced by pathogen infection. Some simple eLRR genes are responsive to abiotic stresses: OsLRR1 and CaLRR1 are responsive to mechanical wounding [9,55], and NtLRR2 and CaLRR1 are responsive to salt treatment $[29,55]$. Moreover, some simple eLRR genes respond differently to phytohormone treatment. In pepper, for example, CaLRR1 is induced by ABA treatment but not by treatment with SA, MeJA or ET [55], whereas SbLRR2 is strongly induced by MeJA but not by SA or 1-aminocyclopropane-1-carboxylic acid (ACC) [27]. In addition, the transcript levels of several simple eLRR genes are reported to be tissue-specific. For example, NtLRR2 is mainly expressed in roots rather than in stems and leaves [29]. LRRop-1 from Arabidopsis is enriched in seeds and rosette leaves [56]. We observed that OsI-BAK1 was induced by mechanical wounding, infestation with BPH and WBPH and treatment with MeJA and ABA (Figure 2). Together, these data suggest that each simple eLRR gene is expressed in particular tissues and responds differently to biotic and abiotic stresses, thereby playing different roles in plant growth, development and defenses against various stresses.

The subcellular localization of eLRR proteins has been researched extensively. Among these, LRR-RLKs and LRR-RLPs are plasma membrane-localized proteins [57,58], whereas PGIP-like proteins and leucine-rich repeat extensin-like proteins are cell wall-localized [59,60]. The subcellular localization of simple eLRR proteins is complicated. CaLRR1 in pepper, for instance, is localized to the cytoplasm and plasma membrane and can be secreted into the apoplastic space [30]. OsLRR1 is localized to the endosomal pathway [9]. These proteins may also be localized to the endoplasmic reticulum $[28,56]$ or extracellular space [61]. Like the subcellular localization of NtLRR2 [29] and CaLRR1 [30], both of which play an important role in the resistance of plants to pathogens, OsI-BAK1 is localized to plasma membranes (Figure 1c). This result demonstrates that OsI-BAK1, in addition to its functions in grain filling, leaf development [43] and herbivore resistance reported in this study, may also play a role in plants' resistance to disease. This hypothesis needs to be confirmed in the future.

Both MPKs and WRKY transcription factors play a central role in herbivore-induced plant defense responses via modulating defensive signaling pathways, such as those mediated by JA, SA and ethylene [47,62]. Moreover, MPKs and WRKY transcription factors can regulate each other at the transcriptional and translational levels [34,48]. In this study, although silencing OsI-BAK1 increased the transcript level of OsMPK3, it did not influence the activity of OsMPK3 or the transcript level and activity of OsMPK6 (Figures 4a and S5). However, we did observe that silencing OsI-BAK1 upregulated the transcript levels of OsWRKY24, OsWRKY53 and OsWRKY70 (Figure 4b-d). Moreover, silencing OsI-BAK1 decreased the BPH-induced levels of ET (Figure 5a) but not JA, JA-Ile, ABA, SA and $\mathrm{H}_{2} \mathrm{O}_{2}$ (Figure S6). Given that both OsWRKY53 and OsWRKY70 regulate herbivore-induced levels of ET in rice $[33,34,48]$, we think that the decrease in BPH-induced ET levels in ir-ibak1 plants is probably related to the change in transcript levels of OsWRKY53 and OsWRKY70. Why the levels of these WRKY transcripts and of ET in ir-ibak1 plants changed bears further study.

The ET-mediated signaling pathway plays an important role in the resistance of plants to herbivores $[1,6]$. In rice, it has been reported that the ET pathway negatively regulates the resistance of plants to BPH [36]: BPH preferred to feed and oviposit on the WT plants over plants with ET deficiency; moreover, in $\mathrm{BPH}$, the levels of honeydew excretion were reduced, and in plants with ET deficiency, natural enemies became more attractive. Here, we observed a similar result: BPH preferred to oviposit on WT plants over ir-ibak1 
plants. In addition, the exogenous application of ethephon on the ir-ibak1 lines abolished the difference in $\mathrm{BPH}$ oviposition preference (Figure 7), suggesting that the decreased oviposition preference of BPH for ir-ibak1 plants depends on the ET pathway (as we found previously) [36]. Interestingly, we did not find that the exogenous application of ethephon on ir-ibak1 plants restored the hatching rate of BPH eggs (Figure S7), demonstrating that other signaling pathways or components regulated the survival of BPH eggs laid on ir-ibak1 plants. It will be interesting to identify these pathways or components in the future.

ET has been reported to negatively regulate root growth [63]. Moreover, in rice, the overexpression of OsERF2 reduces the root length [53]. The root length in ir-ibak1 plants was longer and the levels of ET and OsERF2 transcripts were lower than in WT plants. Thus, the longer root length phenotype exhibited in ir-ibak1 plants compared to WT plants may also be related to the impaired ET signaling pathway. Whether other components are involved in this process remains to be elucidated.

In summary, our results show that a plasma-membrane-localized simple eLRR protein, OsI-BAK1, functions as a negative regulator in the defense response of rice to BPH. BPH can benefit by exploiting this regulator, i.e., inducing the expression of OsI-BAK1, which then decreases the transcript levels of OsMPK3, OsWRKY24, OsWRKY53 and OsWRKY70 and increases the BPH-induced ET levels, changes that promote a susceptibility to BPH in the host plant. These findings demonstrate how BPH regulates host plant resistance, namely by influencing an early signaling factor.

\section{Materials and Methods}

\subsection{Plant Growth and Insects}

In this study, the rice (Oryza sativa L.) genotypes were Xiushui 11 (wild-type, WT) and transgenic lines with silenced OsI-BAK1 (ir-ibak1 lines) (see below). Pregerminated seeds of different lines were cultured in plastic culture dishes (diameter $90 \mathrm{~mm}$, height $15 \mathrm{~mm}$ ) in an incubator at $28 \pm 2{ }^{\circ} \mathrm{C}$ with a 14 -h light period. Ten-day-old seedlings were transferred to hydroponic boxes $(20 \mathrm{~L})$ containing a rice nutrient solution [64] and kept in a greenhouse $\left(28 \pm 2{ }^{\circ} \mathrm{C}, 14\right.$-h light, $55-65 \%$ relative humidity). Twenty to twentyfive days later, plants were transplanted into individual 300-mL hydroponic plastic pots containing a nutrient solution (Figure S1). Plants were used for different experiments $4 \mathrm{~d}$ after transplantation. Colonies of BPH and white-backed planthopper (WBPH) Sogatella furcifera were originally collected from rice fields in Hangzhou, China and maintained on plants of TN1, a susceptible rice variety, for more than 10 years in a climate chamber ( $26 \pm 2{ }^{\circ} \mathrm{C}$, 14-h light, $65 \%$ relative humidity).

\subsection{Isolation of OsI-BAK1 cDNA}

The full-length cDNA of OsI-BAK1 was obtained by reverse transcription-polymerase chain reaction (RT-PCR) from the total RNA isolated from WT plants. Specific primers OsIBAK1-F (5'-GACTGCCAGAGCCTCTACCT-3') and OsI-BAK1-R (5'-GTTCATGCTGCCTGG GTACA-3') were designed based on the sequence of OsI-BAK1 (TIGR ID: LOC_Os03g32580). The PCR products were cloned into the $\mathrm{pEASY}^{\circledR}$-Blunt simple cloning vector (TransGen, Beijing, China) and sequenced.

\subsection{Structure and Phylogenetic Analysis of OsI-BAK1}

The structure domain of OsI-BAK1 was analyzed using SMART (http:/ /smart.embl. de/; accessed on 4 January 2020) and the MEME Suite (http:/ / meme-suite.org/; accessed on 4 January 2020). The prediction of the signal peptides was performed using SIGNALP 5.0 (http:/ / www.cbs.dtu.dk/services/SignalP/; accessed on 4 January 2020).

The homologs of OsI-BAK1 from other plant species were identified using BLASTP in the NCBI website (https:/ / blast.ncbi.nlm.nih.gov/Blast.cgi; accessed on 10 September 2021). The full-length amino acid sequences of OsI-BAK1 were set as query sequences and blasted with the default parameters. The amino acid sequences were downloaded from the website and aligned by ClustalW in MEGA-X (pairwise alignment: gap opening 
penalty 10.00, gap extension penalty 0.10 ; multiple alignment: gap opening penalty 10.00 , gap extension penalty 0.20 ; use negative matrix: off, delay divergent cutoff $30 \%$ ) [65]. The alignment results were used to construct a neighbor-joining tree with default parameters similar to a previous study (scope: all selected taxa; statistical method: neighbor-joining; test of phylogeny: bootstrap method, 1000 times of replications; substitutions type: amino acid; model/method: Poisson model; rates among sites: uniform rates; pattern among lineages: same (homogeneous); gaps/missing date treatment: complete deletion; number of threads 3) [22].

\subsection{Subcellular Localization Assay}

For subcellular localization, the full length of OsI-BAK1 was inserted into pCAMBIA1301 and fused with green fluorescent protein (GFP), yielding a transformation plasmid vector (Figure S2a). Protoplast isolation and polyethylene glycol (PEG)-mediated transformation was performed following a method described previously [66]. Briefly, rice protoplasts were prepared from leaf sheaths of seedlings of rice variety Nipponbare at a concentration of $2 \times 10^{6}$ cells $/ \mathrm{mL}$. Ten micrograms of plasmid DNA (pCAMBIA1301-OsIBAK1-GFP) was mixed with $100 \mu \mathrm{L}$ of protoplasts and $110 \mu \mathrm{L}$ of $40 \%$ PEG-calcium transfection solution $\left(40 \%(w / v)\right.$ PEG4000 in $\mathrm{ddH}_{2} \mathrm{O}$ containing $0.2 \mathrm{M}$ of mannitol and $100 \mathrm{mM}$ of $\mathrm{CaCl}_{2}$ for $5 \mathrm{~min}$. The reaction was stopped by adding $400 \mu \mathrm{L}$ of W5 solution ( $0.1 \%$ glucose, $0.08 \% \mathrm{KCl}, 0.9 \% \mathrm{NaCl}, 1.84 \% \mathrm{CaCl}_{2} \cdot 2 \mathrm{H}_{2} \mathrm{O}$ and 2-mM MES $\cdot \mathrm{KOH}$ (pH 5.7)). The solution was centrifuged, the supernatant was removed and the remainder was incubated in the dark for $16-20 \mathrm{~h}$ at $26^{\circ} \mathrm{C}$. Transformed protoplasts were imaged under a confocal microscope (LSM 800, Zeiss, Oberkochen, Germany). The plasmid pBIN-AtPIP2A-mCherry [22] was used as a positive control for membrane localization. The chemical compounds mentioned above were all obtained from Sigma-Aldrich (Darmstadt, Germany).

\subsection{Plant Treatment}

For mechanical wounding, plant shoots (lower part, approximately $2 \mathrm{~cm}$ long) were individually pierced 200 times with a needle. Nonmanipulated plants were used as controls. For BPH or WBPH treatment, plant shoots were individually infested with 15 gravid females of $\mathrm{BPH}$ or WBPH, each of which was confined in a glass cage (diameter $40 \mathrm{~mm}$, height $80 \mathrm{~mm}$, with 24 small holes, diameter $0.8 \mathrm{~mm}$ ) (Figure S1). Plants with empty cages were used as controls. For the MeJA (Sigma-Aldrich, Darmstadt, Germany) or ABA (Aladdin, Shanghai, China) treatment, according to our previous experiments [67], MeJA or ABA was first dissolved in a small volume of ethanol $(100 \%)$ and then added to the nutrient solution until its concentration reached 100- $\mu \mathrm{M}$. Plants grown in the nutrient solution with an equal volume of ethanol $(100 \%)$ but without MeJA or ABA were used as controls. For ethephon treatment, ethephon (Aladdin, Shanghai, China) was dissolved in $\mathrm{ddH}_{2} \mathrm{O}$ (with $0.02 \%$ Tween-20), and then, each plant was sprayed thoroughly with $500-\mu \mathrm{M}$ or 1-mM ethephon solution. Controls were sprayed with equal volumes of $0.02 \%$ Tween-20 in $\mathrm{ddH}_{2} \mathrm{O}$.

\subsection{RNA Extraction and Real Time-qPCR}

In these experiments, five independent biological samples were used. Total RNA was extracted from $100 \mathrm{mg}$ of rice leaf sheaths using the MiniBEST Plant RNA Extraction Kit (TaKaRa, Dalian, China). Five hundred nanograms of each total RNA sample was reversetranscribed by using PrimeScript ${ }^{\mathrm{TM}}$ RT Master Mix (TaKaRa, Dalian, China) according to the manufacturer's protocols. The real-time qPCR assay was performed on the CFX96 Real-Time System (Bio-Rad, Richmond, CA, USA), using TB Green ${ }^{\circledR}$ Premix Ex Taq ${ }^{\mathrm{TM}}$ II or Premix Ex Taq ${ }^{\mathrm{TM}}$ (Probe qPCR) (TaKaRa, Dalian, China) following the manufacturer's protocols. A linear standard curve, threshold cycle number versus $\log _{10}$ (designated transcript level), was built using a series of concentrations of a specific cDNA standard, and the relative expression levels of the transcripts of different genes were determined according to the standard curve. A rice actin gene, OsACTIN (TIGR ID: LOC_Os03g50885), 
was used as an internal standard to normalize the cDNA concentrations. All primers and probes of the target genes used for real-time qPCR are listed in Table S1.

\subsection{Generation and Characterization of Transgenic Plants}

To prepare the RNAi construct, a 520-bp fragment of OsI-BAK1 was cloned into the pCAMBIA1301-RNAi vector (Figure S2b). This vector was inserted into rice variety Xiushui 11 using Agrobacterium tumefaciens-mediated transformation. Rice transformation, screening of the homozygous $\mathrm{T}_{2}$ plants and identification of the number of insertions by Southern blot were performed following a method described previously [38]. The silencing efficacy of OsI-BAK1 in the ir-ibak1 lines was performed using real-time qPCR with primers irIBAK1-F (5'-GGCCTTCACCCTCTTCTACT-3') and irIBAK1-R (5'-GTCGTAGGTAGAGGCTCTGG$3^{\prime}$ ). Two homozygous $T_{2}$ lines (irIBAK1-1 and irIBAK1-2) with a single insertion were selected and used in the following experiments.

\subsection{Measurement of Plant Growth Parameters}

Plant growth parameters of the 30- and 40-day-old WT plants and of the ir-ibak1 plants were measured. These plant growth parameters included the root length, shoot height, plant mass and chlorophyll content. The root length was measured from the shoot base to the longest root tip. The shoot height was measured from the shoot base to the longest leaf apex. The whole weight of the plant was regarded as the plant mass. For the chlorophyll content determination, the youngest three fully expanded leaves from each plant and three locations (at the tip, middle and base of the leaf) from each leaf were measured by a chlorophyll meter, SPAD-502 Plus (Tokyo, Japan). The experiments above were replicated 10 times.

\subsection{BPH Bioassay}

To investigate the effect of OsI-BAK1 on the hatching rate of the BPH eggs, the WT and ir-ibak1 plants were individually confined in glass cages, and 15 gravid BPH females were introduced into each cage (Figure S1). Twelve hours later, the females were removed, and the number of newly hatched nymphs on each plant was counted every day until no newborn nymphs appeared for three consecutive days. The unhatched eggs in each plant were counted under a microscope to calculate the hatching rate. The experiments for each line were replicated 10 times.

To assess the influence of silencing OsI-BAK1 on the survival rate of BPH nymphs, the $\mathrm{WT}$ and ir-ibak1 plants were individually confined in glass cages, and 15 newly hatched $\mathrm{BPH}$ nymphs were released into each cage (Figure S1). The surviving nymphs on each plant were recorded daily until all of them became adults. The experiments for each line were replicated 10 times.

To observe the impact of OsI-BAK1 on the BPH oviposition preference, pots with two plants-an irIBAK1-1 plant and a WT plant or an irIBAK1-2 plant and a WT plant-were individually confined in glass cages (see Figure S1 but with two plants). Fifteen gravid $\mathrm{BPH}$ females were released into each cage. Two days later, the insects were removed, and the number of eggs on each plant was counted under a microscope. The experiment was replicated 10 times.

\subsection{Detection of MPK Activation}

Plants of the WT and two ir-ibak1 lines were randomly assigned to BPH and control treatments. The outermost part of two leaf sheaths that were infested by gravid $\mathrm{BPH}$ females was harvested at 0,1 and $3 \mathrm{~h}$ after BPH infestation. The experiments for each treatment at each time point were replicated five times. The sample containing five replications was mixed and ground together, and $100 \mathrm{mg}$ of each sample was used to extract the total proteins and detect the MPK activation according to a method described previously [39]. The quantitative results were calculated after repeating this experiment for four times using ImageJ (https:/ /imagej.nih.gov/ij/; accessed on 16 July 2021). The relative kinase 
activation of OsMPK3 and OsMPK6 was calculated by taking the signal intensity of the WT sample without BPH infestation (at $0 \mathrm{~h}$ ) as 1 for normalization.

\subsection{1. $\mathrm{SA}, \mathrm{JA}$, JA-Ile, $\mathrm{ABA}$ and $\mathrm{H}_{2} \mathrm{O}_{2}$ Analysis}

Plants of the WT and two transgenic lines were randomly assigned to BPH and control treatments. The outermost part of two leaf sheaths that were infested by gravid $\mathrm{BPH}$ females was harvested at 0, 8, 24 and $48 \mathrm{~h}$ after BPH infestation. The SA, JA, JA-Ile and ABA were extracted with ethyl acetate spiked with labeled internal standards $\left({ }^{2} \mathrm{D} 6-\mathrm{JA}\right.$, ${ }^{2}$ D6-JA-Ile, ${ }^{2}$ D4-SA and ${ }^{2}$ D6-ABA) and analyzed using a HPLC/mass spectrometry/mass spectrometry system [22]. For the $\mathrm{H}_{2} \mathrm{O}_{2}$ analysis, the outermost part of two leaf sheaths was collected at $0,8,12$ and $24 \mathrm{~h}$ after $\mathrm{BPH}$ infestation. The $\mathrm{H}_{2} \mathrm{O}_{2}$ concentration of each sample was measured using the Amplex Red Hydrogen Peroxide/Peroxidase Assay Kit (Invitrogen, Eugene, OR, USA) according to the instructions. The experiments for each treatment at each time point were replicated five times.

\subsection{Ethylene Analysis}

Plants of the WT and two ir-ibak1 lines, each with 15 gravid BPH females, were individually covered in sealed glass cylinders (diameter $4 \mathrm{~cm}$, height $50 \mathrm{~cm}$ ). ET production was measured at 24,48 and $72 \mathrm{~h}$ after BPH infestation by gas chromatography according to the method [36]. The experiments for each line at each time point were replicated eight times.

\subsection{Data Analysis}

Two-treatment data were analyzed using Student's $t$-tests. Data from three or more treatments were compared using one-way ANOVA followed by Tukey's HSD post-hoc tests. All tests were carried out with SPSS software version 18 (IBM Corp., Armonk, NY, USA).

Supplementary Materials: The following are available online at https:/ / www.mdpi.com/article/10 $.3390 /$ ijms222212182/s1.

Author Contributions: Conceptualization, Y.L.; Methodology, Y.L. and M.Y. (Miaofen Ye); Validation, Y.L. and M.Y. (Miaofen Ye); Formal Analysis, Y.L. and M.Y. (Miaofen Ye); Investigation, M.Y. (Miaofen Ye), P.K., S.C., N.L., M.Y. (Meng Ye) and L.H.; Resources, Y.L.; Data Curation, M.Y. (Miaofen Ye); Writing-Original Draft Preparation, M.Y. (Miaofen Ye); Writing-Review and Editing, Y.L.; Supervision, Y.L.; Project Administration, Y.L. and Funding Acquisition, Y.L. All authors have read and agreed to the published version of the manuscript.

Funding: This work was jointly supported by the National Natural Science Foundation of China (31930091) and the earmarked fund for China Agriculture Research System (CARS-01-43).

Institutional Review Board Statement: Not applicable.

Informed Consent Statement: Not applicable.

Data Availability Statement: Not applicable.

Acknowledgments: We are grateful to Guilan Dong and Lianggen Xie for their assistance with the plant growth and insect rearing. We thank Emily Wheeler for the editorial assistance.

Conflicts of Interest: The authors declare no conflict of interest.

\section{References}

1. Erb, M.; Reymond, P. Molecular interactions between plants and insect herbivores. Annu. Rev. Plant Biol. 2019, 70, 527-557. [CrossRef] [PubMed]

2. Wu, J.; Baldwin, I.T. New insights into plant responses to the attack from insect herbivores. Annu. Rev. Genet. 2010, 44, 1-24. [CrossRef] [PubMed]

3. Arimura, G.; Ozawa, R.; Maffei, M.E. Recent advances in plant early signaling in response to herbivory. Int. J. Mol. Sci. 2011, 12, 3723-3739. [CrossRef] [PubMed]

4. Furstenberg-Hagg, J.; Zagrobelny, M.; Bak, S. Plant defense against insect herbivores. Int. J. Mol. Sci. 2013, 14, $10242-10297$. [CrossRef] 
5. Schuman, M.C.; Baldwin, I.T. The layers of plant responses to insect herbivores. Annu. Rev. Entomol. 2016, 61, 373-394. [CrossRef]

6. Stahl, E.; Hilfiker, O.; Reymond, P. Plant-arthropod interactions: Who is the winner? Plant J. 2018, 93, 703-728. [CrossRef]

7. Park, Y.H.; Choi, C.; Park, E.M.; Kim, H.S.; Park, H.J.; Bae, S.C.; Ahn, I.; Kim, M.G.; Park, S.R.; Hwang, D.J. Over-expression of rice leucine-rich repeat protein results in activation of defense response, thereby enhancing resistance to bacterial soft rot in Chinese cabbage. Plant Cell Rep. 2012, 31, 1845-1850. [CrossRef]

8. Van der Hoorn, R.A.L.; Wulff, B.B.H.; Rivas, S.; Durrant, M.C.; van der Ploeg, A.; de Wit, P.J.G.M.; Jones, J.D.G. Structure-function analysis of Cf-9, a receptor-like protein with extracytoplasmic leucine-rich repeats. Plant Cell 2005, 17, 1000-1015. [CrossRef]

9. Zhou, L.; Cheung, M.Y.; Zhang, Q.; Lei, C.L.; Zhang, S.H.; Sun, S.S.; Lam, H.M. A novel simple extracellular leucine-rich repeat (eLRR) domain protein from rice (OsLRR1) enters the endosomal pathway and interacts with the hypersensitive-induced reaction protein 1 (OsHIR1). Plant Cell Environ. 2009, 32, 1804-1820. [CrossRef]

10. Couto, D.; Zipfel, C. Regulation of pattern recognition receptor signalling in plants. Nat. Rev. Immunol. 2016, 16, 537-552. [CrossRef]

11. Van der Burgh, A.M.; Joosten, M. Plant immunity: Thinking outside and inside the box. Trends Plant Sci. 2019, $24,587-601$. [CrossRef]

12. Wang, W.; Feng, B.; Zhou, J.M.; Tang, D. Plant immune signaling: Advancing on two frontiers. J. Integr. Plant Biol. 2020, 62, 2-24. [CrossRef]

13. Chinchilla, D.; Bauer, Z.; Regenass, M.; Boller, T.; Felix, G. The Arabidopsis receptor kinase FLS2 binds flg22 and determines the specificity of flagellin perception. Plant Cell 2006, 18, 465-476. [CrossRef]

14. Gómez-Gómez, L.; Boller, T. FLS2: An LRR receptor-like kinase involved in the perception of the bacterial elicitor flagellin in Arabidopsis. Mol. Cell 2000, 5, 1003-1011. [CrossRef]

15. Sun, Y.; Li, L.; Macho, A.P.; Han, Z.; Hu, Z.; Zipfel, C.; Zhou, J.M.; Chai, J. Structural basis for flg22-induced activation of the Arabidopsis FLS2-BAK1 immune complex. Science 2013, 342, 624-628. [CrossRef]

16. Mithoe, S.C.; Menke, F.L. Regulation of pattern recognition receptor signalling by phosphorylation and ubiquitination. Curr. Opin. Plant Biol. 2018, 45, 162-170. [CrossRef]

17. Zhou, Z.; Zhao, Y.; Bi, G.; Liang, X.; Zhou, J.M. Early signalling mechanisms underlying receptor kinase-mediated immunity in plants. Philos. Trans. R. Soc. Lond. B Biol. Sci. 2019, 374, 20180310. [CrossRef]

18. Luu, D.D.; Joe, A.; Chen, Y.; Parys, K.; Bahar, O.; Pruitt, R.; Chan, L.J.G.; Petzold, C.J.; Long, K.; Adamchak, C.; et al. Biosynthesis and secretion of the microbial sulfated peptide RaxX and binding to the rice XA21 immune receptor. Proc. Natl. Acad. Sci. USA 2019, 116, 8525-8534. [CrossRef]

19. Pruitt, R.N.; Schwessinger, B.; Joe, A.; Thomas, N.; Liu, F.; Albert, M.; Robinson, M.R.; Chan, L.J.; Luu, D.D.; Chen, H.; et al. The rice immune receptor XA21 recognizes a tyrosine-sulfated protein from a Gram-negative bacterium. Sci. Adv. 2015, 1, e1500245. [CrossRef]

20. Song, W.; Wang, G.; Chen, L.; Kim, H.S.; Pi, L.; Holsten, T.; Gardner, J.; Wang, B.; Zhai, W.; Zhu, L.; et al. A receptor kinase-like protein encoded by the rice disease resistance gene, Xa21. Science 1995, 270, 1804-1806. [CrossRef]

21. Wang, G.L.; Song, W.Y.; Ruan, D.L.; Sideris, S.; Ronald, P.C. The cloned gene, Xa21, confers resistance to multiple Xanthomonas oryzae pv. oryzae isolates in transgenic plants. Mol. Plant. Microbe Interact. 1996, 9, 850-855. [CrossRef] [PubMed]

22. Hu, L.; Ye, M.; Kuai, P.; Ye, M.; Erb, M.; Lou, Y. OsLRR-RLK1, an early responsive leucine-rich repeat receptor-like kinase, initiates rice defense responses against a chewing herbivore. New Phytol. 2018, 219, 1097-1111. [CrossRef] [PubMed]

23. Steinbrenner, A.D.; Munoz-Amatriain, M.; Chaparro, A.F.; Aguilar-Venegas, J.M.; Lo, S.; Okuda, S.; Glauser, G.; Dongiovanni, J.; Shi, D.; Hall, M.; et al. A receptor-like protein mediates plant immune responses to herbivore-associated molecular patterns. Proc. Natl. Acad. Sci. USA 2020, 117, 31510-31518. [CrossRef] [PubMed]

24. Kirsch, R.; Vurmaz, E.; Schaefer, C.; Eberl, F.; Sporer, T.; Haeger, W.; Pauchet, Y. Plants use identical inhibitors to protect their cell wall pectin against microbes and insects. Ecol. Evol. 2020, 10, 3814-3824. [CrossRef]

25. Tornero, P.; Mayda, E.; Gomez, M.D.; Canas, L.; Conejero, V.; Vera, P. Characterization of LRP, a leucine-rich repeat (LRR) protein from tomato plants that is processed during pathogenesis. Plant J. 1996, 10, 315-330. [CrossRef]

26. Hipskind, J.D.; Nicholson, R.L.; Goldsbrough, P.B. Isolation of a cDNA encoding a novel leucine-rich repeat motif from Sorghum bicolor inoculated with fungi. Mol. Plant. Microbe Interact. 1996, 9, 819-825. [CrossRef]

27. Zhu, F.-Y.; Li, L.; Zhang, J.; Lo, C. Transgenic expression of a sorghum gene (SbLRR2) encoding a simple extracellular leucine-rich protein enhances resistance against necrotrophic pathogens in Arabidopsis. Physiol. Mol. Plant Pathol. 2015, 91, 31-37. [CrossRef]

28. Jacques, A.; Ghannam, A.; Erhardt, M.; de Ruffray, P.; Baillieul, F.; Kauffmann, S. NtLRP1, a tobacco leucine-rich repeat gene with a possible role as a modulator of the hypersensitive response. Mol. Plant. Microbe Interact. 2006, 19, 747-757. [CrossRef]

29. Xu, Z.; Xiong, T.; Ni, Z.; Chen, X.; Chen, M.; Li, L.; Gao, D.; Yu, X.; Liu, P.; Ma, Y. Isolation and identification of two genes encoding leucine-rich repeat (LRR) proteins differentially responsive to pathogen attack and salt stress in tobacco. Plant Sci. 2009, 176, 38-45. [CrossRef]

30. Hong, J.K.; Hwang, I.S.; Hwang, B.K. Functional roles of the pepper leucine-rich repeat protein and its interactions with pathogenesis-related and hypersensitive-induced proteins in plant cell death and immunity. Planta 2017, 246, 351-364. [CrossRef]

31. Caddell, D.F.; Park, C.J.; Thomas, N.C.; Canlas, P.E.; Ronald, P.C. Silencing of the rice gene LRR1 compromises rice Xa21 transcript accumulation and XA21-mediated immunity. Rice 2017, 10, 23. [CrossRef] 
32. Lou, Y.; Zhang, G.; Zhang, W.; Hu, Y.; Zhang, J. Biological control of rice insect pests in China. Biol. Control 2013, 67, 8-20. [CrossRef]

33. Hu, L.; Ye, M.; Li, R.; Lou, Y. OsWRKY53, a versatile switch in regulating herbivore-induced defense responses in rice. Plant Plant Signal. Behav. 2016, 11, e1169357. [CrossRef]

34. Li, R.; Zhang, J.; Li, J.; Zhou, G.; Wang, Q.; Bian, W.; Erb, M.; Lou, Y. Prioritizing plant defence over growth through WRKY regulation facilitates infestation by non-target herbivores. eLife 2015, 4, e04805. [CrossRef]

35. Lu, J.; Ju, H.; Zhou, G.; Zhu, C.; Erb, M.; Wang, X.; Wang, P.; Lou, Y. An EAR-motif-containing ERF transcription factor affects herbivore-induced signaling, defense and resistance in rice. Plant J. 2011, 68, 583-596. [CrossRef]

36. Lu, J.; Li, J.; Ju, H.; Liu, X.; Erb, M.; Wang, X.; Lou, Y. Contrasting effects of ethylene biosynthesis on induced plant resistance against a chewing and a piercing-sucking herbivore in rice. Mol. Plant 2014, 7, 1670-1682. [CrossRef]

37. Zheng, X.; Zhu, L.; He, G. Genetic and molecular understanding of host rice resistance and Nilaparvata lugens adaptation. Curr. Opin. Insect Sci. 2021, 45, 14-20. [CrossRef]

38. Zhou, G.; Qi, J.; Ren, N.; Cheng, J.; Erb, M.; Mao, B.; Lou, Y. Silencing OsHI-LOX makes rice more susceptible to chewing herbivores, but enhances resistance to a phloem feeder. Plant J. 2009, 60, 638-648. [CrossRef]

39. Ye, M.; Kuai, P.; Hu, L.; Ye, M.; Sun, H.; Erb, M.; Lou, Y. Suppression of a leucine-rich repeat receptor-like kinase enhances host plant resistance to a specialist herbivore. Plant Cell Environ. 2020, 43, 2571-2585. [CrossRef]

40. Zhang, J.; Luo, T.; Wang, W.; Cao, T.; Li, R.; Lou, Y. Silencing OsSLR1 enhances the resistance of rice to the brown planthopper Nilaparvata lugens. Plant Cell Environ. 2017, 40, 2147-2159. [CrossRef]

41. Xu, J.; Wang, X.; Zu, H.; Zeng, X.; Baldwin, I.T.; Lou, Y.; Li, R. Molecular dissection of rice phytohormone signaling involved in resistance to a piercing-sucking herbivore. New Phytol. 2021, 230, 1639-1652. [CrossRef]

42. Zeng, J.; Zhang, T.; Huangfu, J.; Li, R.; Lou, Y. Both allene oxide synthases genes are involved in the biosynthesis of herbivoreinduced jasmonic acid and herbivore resistance in rice. Plants 2021, 10, 442. [CrossRef]

43. Khew, C.Y.; Teo, C.J.; Chan, W.S.; Wong, H.L.; Namasivayam, P.; Ho, C.L. Brassinosteroid insensitive 1-associated kinase 1 (OsI-BAK1) is associated with grain filling and leaf development in rice. J. Plant Physiol. 2015, 182, 23-32. [CrossRef]

44. Viana, V.E.; Busanello, C.; da Maia, L.C.; Pegoraro, C.; de Oliveira, A.C. Activation of rice WRKY transcription factors: An army of stress fighting soldiers? Curr. Opin. Plant Biol. 2018, 45, 268-275. [CrossRef]

45. Zhang, M.; Su, J.; Zhang, Y.; Xu, J.; Zhang, S. Conveying endogenous and exogenous signals: MAPK cascades in plant growth and defense. Curr. Opin. Plant Biol. 2018, 45, 1-10. [CrossRef]

46. Shen, X.; Yuan, B.; Liu, H.; Li, X.; Xu, C.; Wang, S. Opposite functions of a rice mitogen-activated protein kinase during the process of resistance against Xanthomonas oryzae. Plant J. 2010, 64, 86-99. [CrossRef]

47. Wang, Q.; Li, J.; Hu, L.; Zhang, T.; Zhang, G.; Lou, Y. OsMPK3 positively regulates the JA signaling pathway and plant resistance to a chewing herbivore in rice. Plant Cell Rep. 2013, 32, 1075-1084. [CrossRef]

48. Hu, L.; Ye, M.; Li, R.; Zhang, T.; Zhou, G.; Wang, Q.; Lu, J.; Lou, Y. The rice transcription factor WRKY53 suppresses herbivoreinduced defenses by acting as a negative feedback modulator of mitogen-activated protein kinase activity. Plant Physiol. 2015, 169, 2907-2921.

49. Yokotani, N.; Shikata, M.; Ichikawa, H.; Mitsuda, N.; Ohme-Takagi, M.; Minami, E.; Nishizawa, Y. OsWRKY24, a blast-disease responsive transcription factor, positively regulates rice disease resistance. J. Gen. Plant Pathol. 2018, 84, 85-91. [CrossRef]

50. Zhou, G.; Ren, N.; Qi, J.; Lu, J.; Xiang, C.; Ju, H.; Cheng, J.; Lou, Y. The 9-lipoxygenase Osr9-LOX1 interacts with the 13lipoxygenase-mediated pathway to regulate resistance to chewing and piercing-sucking herbivores in rice. Physiol. Plant 2014, 152, 59-69. [CrossRef]

51. Guo, Y.; Zhu, C.; Gan, L.; Ng, D.; Xia, K. Ethylene is involved in the complete-submergence induced increase in root iron and manganese plaques in Oryza sativa. Plant Growth Regul. 2014, 76, 259-268. [CrossRef]

52. Rzewuski, G.; Sauter, M. Ethylene biosynthesis and signaling in rice. Plant Sci. 2008, 175, 32-42. [CrossRef]

53. Xiao, G.; Qin, H.; Zhou, J.; Quan, R.; Lu, X.; Huang, R.; Zhang, H. OsERF2 controls rice root growth and hormone responses through tuning expression of key genes involved in hormone signaling and sucrose metabolism. Plant Mol. Biol. 2016, 90, 293-302. [CrossRef] [PubMed]

54. Zhou, L.; Cheung, M.Y.; Li, M.W.; Fu, Y.; Sun, Z.; Sun, S.M.; Lam, H.M. Rice hypersensitive induced reaction protein 1 (OsHIR1) associates with plasma membrane and triggers hypersensitive cell death. BMC Plant Biol. 2010, 10, 290. [CrossRef] [PubMed]

55. Jung, E.H.; Jung, H.W.; Lee, S.C.; Han, S.W.; Heu, S.; Hwang, B.K. Identification of a novel pathogen-induced gene encoding a leucine-rich repeat protein expressed in phloem cells of Capsicum annuum. Biochim. Biophys. Acta 2004, 1676, 211-222. [CrossRef]

56. Ravindran, P.; Yong, S.Y.; Mohanty, B.; Kumar, P.P. An LRR-only protein regulates abscisic acid-mediated abiotic stress responses during Arabidopsis seed germination. Plant Cell Rep. 2020, 39, 909-920. [CrossRef]

57. Lee, D.H.; Lee, H.S.; Belkhadir, Y. Coding of plant immune signals by surface receptors. Curr. Opin. Plant Biol. 2021, 62, 102044. [CrossRef]

58. Reymond, P. Receptor kinases in plant responses to herbivory. Curr. Opin. Biotechnol. 2021, 70, 143-150. [CrossRef]

59. Herger, A.; Dunser, K.; Kleine-Vehn, J.; Ringli, C. Leucine-rich repeat extensin proteins and their role in cell wall sensing. Curr. Biol. 2019, 29, R851-R858. [CrossRef]

60. Kalunke, R.M.; Tundo, S.; Benedetti, M.; Cervone, F.; De Lorenzo, G.; D'Ovidio, R. An update on polygalacturonase-inhibiting protein (PGIP), a leucine-rich repeat protein that protects crop plants against pathogens. Front. Plant Sci. 2015, 6, 146. [CrossRef] 
61. Zhu, F.; Li, L.; Lam, P.; Chen, M.; Chye, M.; Lo, C. Sorghum extracellular leucine-rich repeat protein SbLRR2 mediates lead tolerance in transgenic Arabidopsis. Plant Cell Physiol. 2013, 54, 1549-1559. [CrossRef]

62. Huangfu, J.; Li, J.; Li, R.; Ye, M.; Kuai, P.; Zhang, T.; Lou, Y. The Transcription factor OsWRKY45 negatively modulates the resistance of rice to the brown planthopper Nilaparvata lugens. Int. J. Mol. Sci. 2016, 17, 697. [CrossRef]

63. Yang, C.; Lu, X.; Ma, B.; Chen, S.Y.; Zhang, J.S. Ethylene signaling in rice and Arabidopsis: Conserved and diverged aspects. Mol. Plant 2015, 8, 495-505. [CrossRef]

64. Yoshida, S.; Forno, D.A.; Cock, J.H. Laboratory Manual for Physiological Studies of Rice, 3rd ed.; International Rice Research Institute: Manila, Philippines, 1976; pp. 1-83.

65. Kumar, S.; Stecher, G.; Li, M.; Knyaz, C.; Tamura, K. MEGA X: Molecular evolutionary genetics analysis across computing platforms. Mol. Biol. Evol. 2018, 35, 1547-1549. [CrossRef]

66. You, Q.; Zhai, K.; Yang, D.; Yang, W.; Wu, J.; Liu, J.; Pan, W.; Wang, J.; Zhu, X.; Jian, Y.; et al. An E3 ubiquitin ligase-BAG protein module controls plant innate immunity and broad-spectrum disease resistance. Cell Host Microbe 2016, 20, 758-769. [CrossRef]

67. Zhou, S.; Chen, M.; Zhang, Y.; Gao, Q.; Noman, A.; Wang, Q.; Li, H.; Chen, L.; Zhou, P.; Lu, J.; et al. OsMKK3, a stress-responsive protein kinase, positively regulates rice resistance to Nilaparvata lugens via phytohormone dynamics. Int. J. Mol. Sci. 2019, 20, 3023. [CrossRef] 